\title{
PRIMARY NEUROENDOCRINE TUMORS
}

\author{
Dr. Malik Hussain Jalbani, Dr. Nisar Ahmed Shaikh, Dr. Ghulam Shabir Shaikh, Dr. Akbar Ali Soomro
}

ABSTRACT... Objective: To evaluate clinical presentation and surgical out come of primary neuroendocrine tumors of Kidney, U. bladder and Prostate gland. Design: A Retrospective study. Setting: Urology Department, SMBBMU Larkana. Period: 2001-2011. Patients and Methods: Series of 6 patients of primary neuroendocrine tumors of Kidney, U. bladder and Prostate gland were identified from 1890 cases of urinary tract tumors. Two cases of renal carcinoid, two cases of small cell carcinoma of urinary bladder and two cases of small cell carcinoma of prostate glands. Renal carcinoid tumors presenting with lumbar pain and microscopic haematuria and identified on the ultrasound. Small cell carcinoma of urinary bladder presenting with dysuria, gross haematuria and on ultrasound while small cell carcinoma of prostate gland presenting with irritatory and obstructive symptoms and confirmed on DRE. Results: 6 patients(5 male and 1 female),Mean age of patients were 45years and range was 35-55 years. All patients treated primarily by definitive surgery like Radical Nephrectomy, TURBT and Pallitive TURP and all tumors confirmed on histopathological examination and referred to LINAR Larkana for proper managements. Conclusions: primary neuroendocrine tumors of Kidney, U.bladder and Prostate gland are rare tumors. Carcinoid tumors have good prognosis but small cell carcinoma have poor prognosis so require prompt treatment.

Key words: Neuroendocrine tumor, Prostate gland, Carcinoid tumor

Article Citation

Jalbani MH, Shaikh NA, Shaikh GS, Soomro AA. Primary neuroendocrine tumors. Professional Med J 2013;20(6): $929-931$.

\section{INTRODUCTION}

Neuroendocrine Tumors are neoplasm that arise from the cells of endocrine and nervous system, many of them are benign. Most commonly occurs in intestine but also found in the lungs and rest of body ${ }^{1,2}$.

They are also called APUDomas because these cells often shows amine precussor(L-Dopa and 5hydroxytriptophane) up take and decarboxylation to produce biogenic amines such as catacholamine and serotinin, Bombesin and calcitonin. They just fueling growth to tumors only ${ }^{1,3}$.

Embrologically arise from neural crest. Prevalance of NETs 35/lac in tumor cases. Among them 2/3 carcinoid and are $1 / 3$ NETs. According to WHO, Neuroendocrine tumors are classified as well differentiated NE tumor (Carcinoid), Well differentiated NE Carcinoma (Atypical Carcinoid), Poorly differentiated NE Carcinoma(Small cell carcinoma) and Large cell NE carcinoma, ${ }^{2,7}$ Our aim of study to identified Neuroendocrine tumors in urinary tract tumor cases and to see there clinical presentation and surgical out come.

\section{PATIENTS AND METHODS}

Series of 6 patients of Primary Neuroendocrine Tumors of Kidney, U.bladder and Prostate gland were seen between 2001-2011 in the department of urology SMBBM University Larkana. Two cases of renal carcinoid, two cases of small cell carcinoma of urinary bladder and two cases of small cell carcinoma of prostate glands identified from 1890 cases of urinary tract tumors. Renal carcinoid tumors presenting with lumbar pain and microscopic haematuria and identified on the ultrasound. Small cell carcinoma of urinary bladder presenting with dysuria, gross haematuria and on ultrasound while small cell carcinoma of prostate gland presenting with irritatory and obstructive symptoms and DRE showed nodular and hard prostate.

\section{RESULTS}

6 patients ( 5 male and 1 female),mean age of patients were $45 y$ ears and range was $35-55$ years. All Patients Diagnosed on clinical presentation and routine ultrasound finding.CT scanning done for staging purpose.All patients treated primary by definitive surgery like Radical Nephrectomy, TURBT and Pallitive 
TURP and 6 Neuroendocrine tumors confirmed on histopathological examination.(Fig.1-3).All patients reffered to LINAR Larkana for proper management.

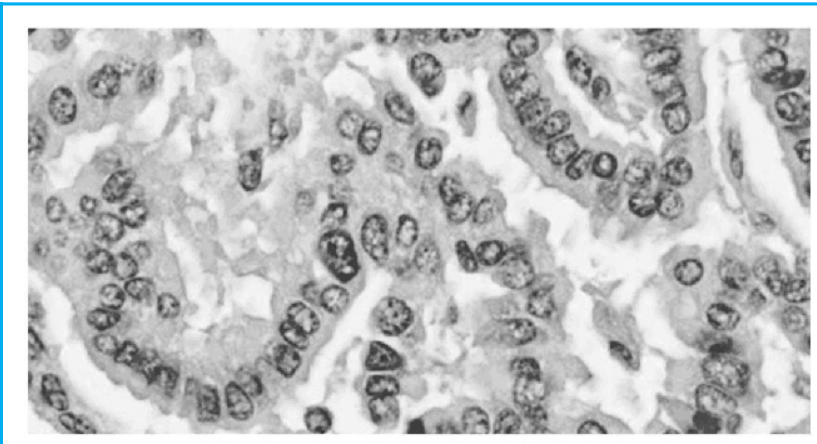

Fig-1. Renal carcinoid tumor

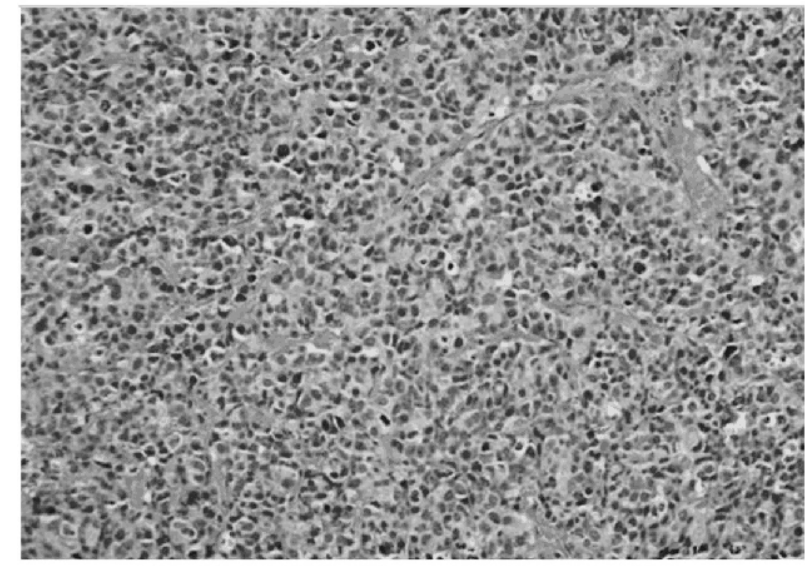

Fig-2. Small cell carcinoma prostate

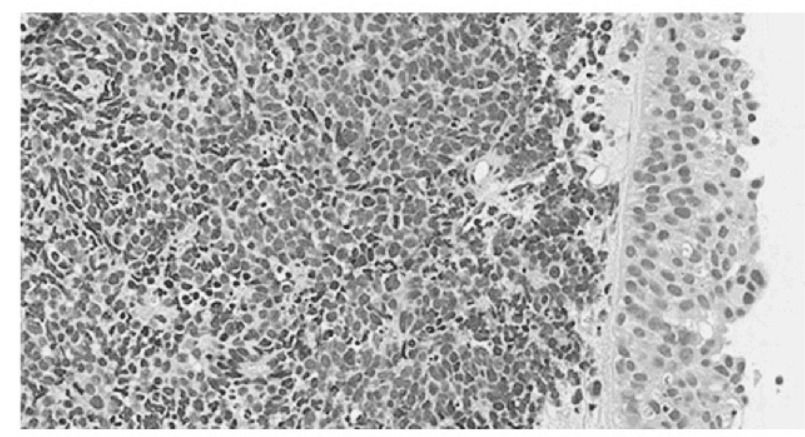

Fig-3. Small cell carcinoma bladder

\section{DISCUSSION}

Overall, primary neuroendocrine tumors of Kidney, U.bladder and Prostate gland.are very rare tumors usually affecting young and middle age. The etiology of Neuroendocrine tumors is DNA Mutation and usually associated with Familial Syndrome like. MEN I and II,
Von-Hipple Linndue Syndrome and Neurofibromatosis ${ }^{1,2}$.

In our study mean age of patients was 45years and range was 35-55 years which is compareable to other studies while none patients associated with familial syndrome because of few cases $^{2,3}$.

Renal carcinoid tumors presenting with lumbar pain and microscopic haematuria and identified on the ultrasound. In some cases Renal carcinoid presenting with Carcinoid Syndrome like Flushing, Diarrhoea. Asthma, CCF, abdominal cramps and peripheral oedema due to serotonin(5HT) or Substance $\mathrm{P}^{3,4}$.

Small cell carcinoma of urinary bladder presenting with dysuria, gross haematuria and identified on ultrasound while small cell carcinoma of prostate gland presenting with irritatory and obstructive symptoms and on DRE prostate nodular and hard. While CT scanning done for staging purpose, which is compareable to Cerulli $C$ and Sciarra Sciarra etal ${ }^{6,9}$ studies. However Serum Chromogranin A, Urine 5Hydroxy indole acetic acid, Neuron-Specific Enlase and Synaptophysin, Octreotide Scintigraphy and MRI also indicated in some cases ${ }^{2,7}$. Various treatment options are available for treatment of Neuroendocrine tumors like somatostatin analogues (Octreotide), Interferon, radioactive labelled hormone (Octreotate to litetum-177,Ytrium-90 and indim-111), Radiofrequency ablation and Radical surgery ${ }^{8,10}$.

We managed primary all with definitive surgery like Radical Nephrectomy,TURBT and Pallitive TURP and all tumors confirmed on histopathological examination which is compareable to Cheng $L$ etal and Cerulli $C$ eta $^{1,6}$. Renal carcinoid still on followup while one case of small cell carcinoma of prostate gland expired due to brain metastasis and other lost followup due to reffered to LINAR Larkana.

\section{Copyright $\odot 22$ Jan, 2013.}




\section{REFERENCE}

1. Cheng L, Pan CX, Yang XJ, et al. Small cell carcinoma of the urinary bladder: a clinicopathologic analysis of 64 patients. Cancer 2004; 101:957.

2. Sved P, Gomez P, Manoharan M, et al. Small cell carcinoma of the bladder. BJU Int 2004; 94:12.

3. Zak FG, Jindrak K, Capozzi F. Carcinoidal tumor of the kidney. Ultrastruct Pathol. 1983;4:51-59.

4. Aygun C. Small cell carcinoma of the prostate: a case report and review of the literature. Md Med J 1997; 46: 353-6.

5. Sarma DP, Weilbaecher TG. Small-cell carcinoma of the prostate. Urology 1989; 33: 332-5.

6. Cerulli $C$ etal. Primary metastatic neuroendocrine small cell bladder cancer: a case report and literature review. Urol Int. 2012;88(3): 365-9. Epub 2012.

7. Singh N, Khurana N, Singh M, Arora P. Primary mixed small cell neuroendocrine-adenocarcinoma of the urinary bladder. J Cancer Res Ther. 2011 OctDec;7(4):493-6

8. Kojima Y etal. Primary carcinoid tumor of the kidney: a case report. Hinyokika Kiyo. 2011 Nov;57(11):611.

9. Sciarra A etal. Current diagnostic procedure on neuroendocrine differentiation of prostatecancer. Urologia. 2011 Apr-Jun;78(2):132-6.

10. Lapuk AV etal. From sequence to molecular pathology, and a mechanism driving the neuroendocrine phenotype in prostate cancer. $J$ Pathol. 2012 Jul;227(3):286-97.

\section{AUTHOR(S):}

1. DR. MALIK HUSSAIN JALBANI

Professor of Urology

SMBBMU, Larkana

2. DR. NISAR AHMED SHAIKH

Assistant Professor of Urology

SMBBMU, Larkana

3. DR. GHULAM SHABIR SHAIKH

Associate Professor of Urology

SMBBMU, Larkana
Article received on: 19/10/2012 Accepted for Publication: 22/01/2013 Received after proof reading: 03/12/2013

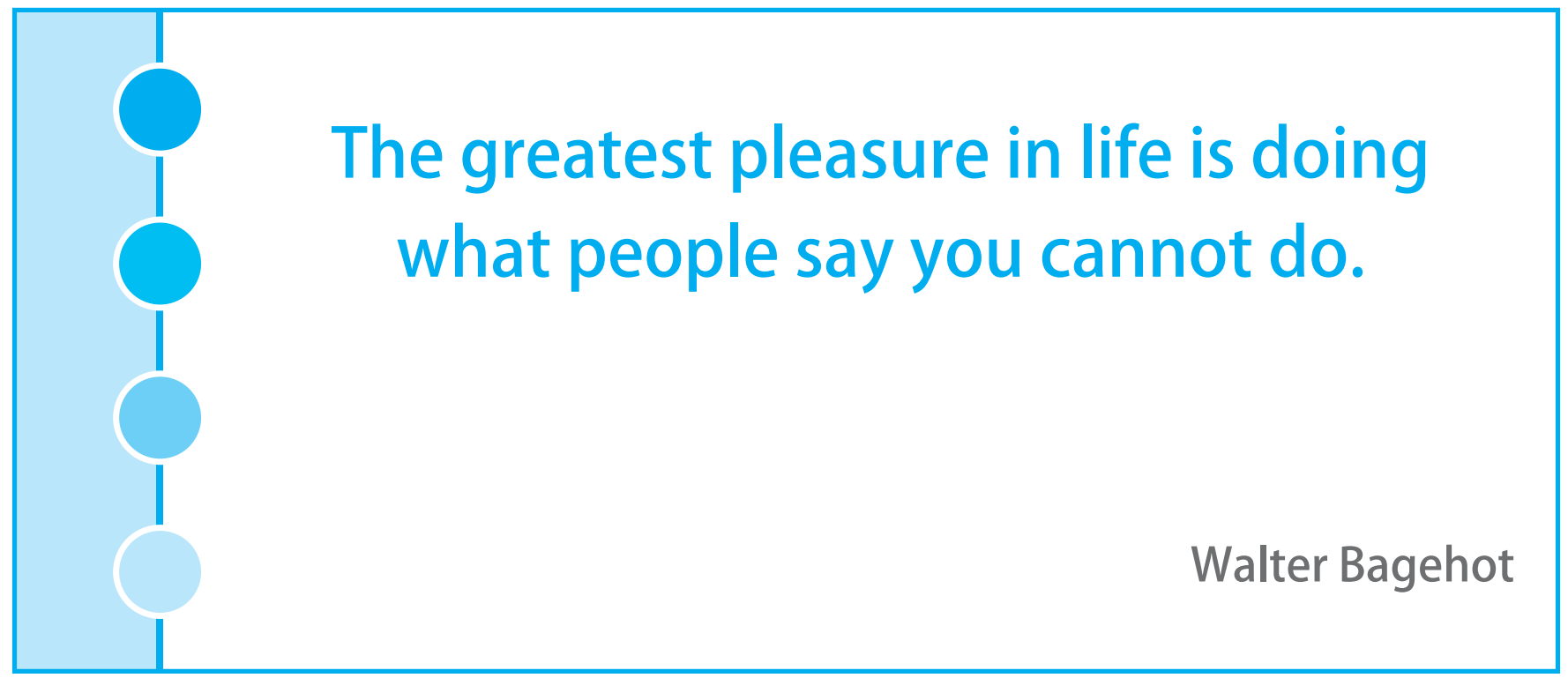

